\title{
Required levels of nasal continuous positive airway pressure dur- ing treatment of obstructive sleep apnoea
}

\author{
F. Sériès, I. Marc, Y. Cormier, J. La Forge
}

\begin{abstract}
Required levels of nasal continuous positive airway pressure during treatment of obstructive sleep apnoea. F. Sériès, I. Marc, Y. Cormier, J. La Forge. (CERS Journals Ltd 1994.

ABSTRACT: The improvement in the severity of obstructive sleep-related breathing disorders during nasal continuous positive airway pressure (NCPAP) therapy can account for the decrease in the required NCPAP level with time. The aim of this study was to prospectively quantify the changes in the required NCPAP level over time of use in sleep apnoea-hypopnoea syndrome (SAHS).

Forty sleep apnoea-hypopnoea patients were evaluated before and during the time course of NCPAP therapy. The effective NCPAP level was defined as the positive pressure level that abolished apnoeic and hypopnoeic events and snoring in all sleep stages and sleep positions. This pressure level was determined within 2 weeks after baseline diagnostic sleep study. Sleep studies with NCPAP and NCPAP titration were performed after $2(n=40), 8(n=40)$, and $20(n=24)$ months of NCPAP therapy.

The initial effective NCPAP level was $9.6 \pm 0.4 \mathrm{cmH}_{2} \mathrm{O}$. It progressively decreased to $8.8 \pm 0.4,7.9 \pm 0.4$ and $7.7 \pm 0.5$ after 2,8 and 20 months, respectively; the difference being significant between the first three NCPAP nights. There was a poor relationship between the changes in the effective NCPAP and changes in weight recorded at the different visits. There was a weak negative relationship between the changes in NCPAP and the previous NCPAP level. In 13 patients, the apnoeahypopnoea index (AHI) remained $>10 n \cdot h^{-1}$ at the first NCPAP trial because the effective NCPAP level was not tolerated. Despite a suboptimal NCPAP level, their sleep architecture improved, and they all reported a subjective improvement in diurnal hypersomnolence. After 2 months of NCPAP therapy, the AHI was $<\mathbf{1 0} n \cdot h^{-1}$ in 11 of these suboptimally treated patients.

We conclude that the required NCPAP level progressively decreases with use. The changes in body weight may play a minor role in the change in the effective NCPAP level.
\end{abstract}

Eur Respir J., 1994, 7, 1776-1781.

\author{
Unité de recherche, Centre de Pneumo- \\ logie de l'hôpital Laval, Université Laval, \\ Québec, Canada. \\ Correspondence: F. Sériès \\ Centre de pneumologie \\ Hôpital Laval \\ 2725 Chemin Ste Foy \\ Sainte Foy (PQ) \\ G1V 4G5 \\ Canada
}

Keywords: Nasal continuous positive airway pressure

sleep apnoea-hypopnoea syndrome

Received: January 191994

Accepted for publication July 51994

Supported by The Respiratory Health Network of Centres of Excellence of Canada.
For the last 12 yrs, nasal continuous positive airway pressure (NCPAP) has been considered one of the most effective treatments of the sleep apnoea-hypopnoea syndrome (SAHS) [1]. NCPAP efficiency in suppressing snoring and sleep-related obstructive breathing disorders, improving apnoea-related oxygen desaturations [2], and haemodynamic disturbances [3, 4], and normalizing sleep architecture and fragmentation [5], can account for the reduction in sleep apnoea-related morbidity and mortality with NCPAP $[6,7]$.

Recent reports suggest that NCPAP benefits may be prolonged after its interruption in SAHS patients [8,9]. RAUSCHER et al. [8] reported that the longest apnoea length decreased when NCPAP was interrupted for part of the night after NCPAP treatments of 6-18 months. LEECH et al. [9] found that the respiratory disturbance index and the average nocturnal saturation significantly improved after 6-46 months of NCPAP therapy. This delayed effect of NCPAP could be attributed to an improvement in upper airway morphology [10], and/or to the correction of sleep fragmentation [11]. This NCPAPinduced improvement in the severity of sleep-related breathing disorders could account for the decrease in the required NCPAP level with time [12]. However, to our knowledge, the time course of the changes in the required effective pressure has not been prospectively evaluated. We therefore do not yet know what is the optimal frequency of control sleep studies to recommend for patients treated with NCPAP.

The beneficial effects of NCPAP have been described in patients receiving an effective pressure level that eliminated snoring and obstructive respiratory disorders $[9,10,13]$. We have previously found that apnoearelated desaturations are improved with NCPAP [2]. Furthermore, in our experience, daytime hypersomnolence is improved in SAHS patients whose apnoea-hypopnoea 
index decreases with NCPAP but who cannot tolerate the optimal NCPAP level. If the improvement of nocturnal breathing disorders induced by NCPAP is of clinical significance, NCPAP use may be accompanied by a progressive decrease in the required level of NCPAP.

The aims of this study were to prospectively determine the changes in the required NCPAP level in SAHS over time of use, and to evaluate the changes in persisting sleep-related breathing disorders with the use of suboptimal NCPAP therapy.

\section{Methods}

\section{Subjects}

Forty five SAHS patients were included in the study. Each patient was evaluated by one of the authors and had conventional polysomnography for clinical suspicion of SAHS. None had undergone previous surgical treatment for sleep-related breathing disorders and none was taking antidepressants, hypnotics or sedatives. The different treatment alternatives were explained to the patients. Those who chose NCPAP therapy after the first sleep study with NCPAP were asked to participate in this study, and all agreed to do so. This first NCPAP trial was performed during a complete sleep recording within 2 weeks after the baseline sleep study, with determination of the effective NCPAP level ( $c f$. infra). Patients were instructed on NCPAP use and installation principles by the sleep technician. The complete instructions on the use of NCPAP machines and nasal mask installation were given at home by the home care company representative. They were treated with the same type of NCPAP apparatus that was used in the sleep laboratory, adjusted at the effective pressure level that was determined during the first NCPAP sleep trial. For a patient to be included in the study, NCPAP had to be applied at least $4 \mathrm{~h} \cdot$ night $^{-1}$ for $\geq 5$ nights $\cdot$ week $^{-1}$, as estimated by regular visits to the patients by a home care company and the records from the meters of the NCAP machines. Five patients who were initially enrolled in the study were eliminated due to failure to respect these criteria.

\section{Determination of the NCPAP effective level}

Determination of the NCPAP effective level was achieved during full night polysomnographic studies, that included the determination of sleep stages (electroencephalogram $\mathrm{C}_{4} \mathrm{~A}_{1}, \mathrm{C}_{3} \mathrm{~A}_{2}$; electro-oculogram; submental electromyogram), nasal and mouth airflow with thermocouples (Grass Instruments, Quincy, MA, USA), arterial oxygen saturation $\left(\mathrm{SaO}_{2}\right)$ with a Criticare 504 ear oximeter (CSI, Waukesha, WI, USA), electrocardiogram and thoracoabdominal movements by respiratory inductive plethysmography (Respitrace, Ambulatory Monitoring, Ardsley, NY, USA) calibrated by the isovolume method [14]. The snoring sound pressure level (SPL) was displayed after the signal of two microphones (Shure SM 58, Evanston, IL, USA) had been preamplified, mixed, equalized (DOD R 831, Salt Lake City, Utah, USA) and analysed with a spectrum analyser (RTA SA 3050, Audio Control, Mountlake Terrace, WA, USA) [15]. All parameters were recorded on a 16-channel polygraph (Model 78; Grass Instruments, Quincy, MA, USA) at a paper speed of $10 \mathrm{~mm} \cdot \mathrm{s}^{-1}$.

Positive pressure level was progressively increased in $1 \mathrm{cmH}_{2} \mathrm{O}$ steps, from $3 \mathrm{cmH}_{2} \mathrm{O}$ until apnoeic and hypopnoeic events, as measured by the apnoea-hypopnoea index (AHI), and snoring were abolished in all sleep stages and all sleep positions, or at the maximal pressure level that was tolerated by the subjects. Polysomnographic recordings were analysed manually in $30 \mathrm{~s}$ epochs, and sleep stages, arousals and respiratory events were defined by standard criteria [16-18]. Snoring was defined as a spike in breathing sound intensity greater than 60 dB SPL. Apnoea, hypopnoea, arousal and snoring indices represent the frequency of these events per hour $\left(n \cdot h^{-1}\right)$ of sleep.

\section{Protocol}

Sleep studies with NCPAP and NCPAP titration were performed after $2(n=40) 8(n=40)$, and $20(n=24)$ months of NCPAP therapy. The number of patients had decreased at the last visit because some of them had not reached the 20 months visit. Subjects were asked to contact the sleep laboratory if they had any trouble with the apparatus. Subjects were asked to avoid consuming alcohol for a minimum of $12 \mathrm{~h}$ preceding each recording session.

\section{Statistical analysis}

Since our data were normally distributed, parametric tests were used. Data expressed as percentages were transformed to obtain an underlying normal distribution [19]. Since our patients were evaluated at different time intervals, the assumption of an equal correlation between the results obtained at the different visits was verified with a sphericity test on orthogonal components [20]. Afterwards, we performed a complete randomized block design, followed by Tukey's test for multiple comparison for each variable. The influence of weight changes and NCPAP values on the changes in the effective NCPAP level at the different visits were analysed by the least square method. Differences were considered significant at a value of $\mathrm{p}<0.05$.

\section{Results}

We analysed the results of forty subjects (34 males and 6 females; age range 35-63 yrs; body mass index $36.3 \pm 1.2 \mathrm{~kg} \cdot \mathrm{m}^{-2}$; mean \pm SEM). The results of the sleep studies were typical of SAHS, with sleep fragmentation and disorganization and nocturnal desaturations (table 1). 
Table 1. - Results of sleep studies with nasal continuous positive airway pressure (NCPAP)

\begin{tabular}{|c|c|c|c|c|c|}
\hline & \multirow{2}{*}{$\begin{array}{l}\text { Baseline } \\
\quad(n=40)\end{array}$} & \multicolumn{4}{|c|}{ NCPAP } \\
\hline & & $\begin{array}{l}\text { First }^{\$} \\
(\mathrm{n}=40)\end{array}$ & $\begin{array}{c}2 \text { months } \\
(\mathrm{n}=40)\end{array}$ & $\begin{array}{c}8 \text { months } \\
(\mathrm{n}=40)\end{array}$ & $\begin{array}{l}20 \text { months } \\
(n=24)\end{array}$ \\
\hline Weight $\mathrm{kg}$ & $100.6 \pm 2.8$ & & $98.3 \pm 2.6$ & $97.8 \pm 2.5$ & $101.1 \pm 2.6$ \\
\hline TST h & $6.1 \pm 0.2$ & $5.9 \pm 0.2$ & $5.9 \pm 0.2$ & $6.2 \pm 0.1$ & $5.8 \pm 0.1$ \\
\hline Stage I-II $\%$ TST & $70.7 \pm 1.9^{\mathrm{a}}$ & $48.7 \pm 2.0^{\mathrm{b}}$ & $61.0 \pm 1.4^{\mathrm{c}}$ & $60.7 \pm 0.9^{c}$ & $61.4 \pm 1.4^{\mathrm{c}}$ \\
\hline Stage III-IV \% TST & $10.6 \pm 1.0^{\mathrm{a}}$ & $26.1 \pm 1.4^{b}$ & $17.9 \pm 0.7^{\mathrm{c}}$ & $16.3 \pm 0.7^{c}$ & $17.6 \pm 1.0^{\mathrm{c}}$ \\
\hline Stage REM \% TST & $19.8 \pm 1.9^{\mathrm{a}}$ & $25.1 \pm 1.6^{b}$ & $21.0 \pm 1.1^{\mathrm{ab}}$ & $22.8 \pm 0.9^{\mathrm{ab}}$ & $20.9 \pm 1.0^{\mathrm{ab}}$ \\
\hline Arousal index $n \cdot h^{-1}$ & $46.9 \pm 4.7^{\mathrm{a}}$ & $11.2 \pm 1.1^{\mathrm{b}}$ & $9.0 \pm 0.8^{b}$ & $8.5 \pm 0.6^{\mathrm{b}}$ & $9.3 \pm 1.1^{\mathrm{b}}$ \\
\hline AHI $n \cdot h^{-1}$ & $48.4 \pm 4.7^{\mathrm{a}}$ & $9.1 \pm 1.4^{\mathrm{b}}$ & $3.8 \pm 0.6^{\mathrm{b}}$ & $3.6 \pm 0.6^{b}$ & $4.9 \pm 0.8^{b}$ \\
\hline$\%$ TST $<80 \% \mathrm{SaO}_{2}$ & $18.9 \pm 4.4^{\mathrm{a}}$ & $2.5 \pm 1.3^{\mathrm{b}}$ & $0.9 \pm 0.8^{\mathrm{b}}$ & $0.1 \pm 0.05^{\mathrm{b}}$ & $0.1 \pm 0.06^{b}$ \\
\hline$\%$ TST supine & $32.7 \pm 4.0^{\mathrm{a}}$ & $46.0 \pm 4.4^{\mathrm{b}}$ & $42.1 \pm 3.9^{\mathrm{ab}}$ & $39.7 \pm 3.8^{\mathrm{ab}}$ & $40.7 \pm 5.9^{\mathrm{ab}}$ \\
\hline
\end{tabular}

Results of the sleep studies realized at the different visits. Data are presented as mean \pm SEM. \$: within 2 weeks of baseline prior to home NCPAP. TST: total sleep time; AHI: apnoea + hypopnoea index; REM: rapid eye movement sleep. Data obtained at the different visits were compared by complete randomized block design, followed by Tukey's test for multiple comparison for each variable. Values superscripted by different letters are significantly different from one another (mean \pm SEM).

As expected, these abnormalities improved with NCPAP (table 1). The effective NCPAP level ranged 5-15 $\mathrm{cmH}_{2} \mathrm{O}$. Interestingly, the percentage of total sleep time (TST) spent in the supine position increased at the first NCPAP trial and remained elevated at the remaining visits. In each patient, diurnal hypersomnolence and alertness subjectively improved with NCPAP.

The effective NCPAP level progressively decreased with time (first NCPAP trial: $9.6 \pm 0.4 \mathrm{cmH}_{2} \mathrm{O}$; after 2 months of NCPAP $8.8 \pm 0.4 \mathrm{cmH}_{2} \mathrm{O}$; after 8 months of NCPAP 7.9 $\pm 0.4 \mathrm{cmH}_{2} \mathrm{O}$; and after 20 months of NCPAP $7.7 \pm 0.5 \mathrm{cmH}_{2} \mathrm{O}$ ), the difference being significant between the first three visits, with no further decrease after 20 months of NCPAP therapy (fig. 1). For the whole group, there was no significant change in weight between the different visits. There was a significant relationship between changes in weight and in the effective NCPAP level ( $\mathrm{r}=0.37 ; \mathrm{p}=<0.0001$ ) (fig. 2). There was a tendency for the decrease in NCPAP to be greater when the initial NCPAP was higher, but the relationship between these two variables was weak $(\mathrm{r}=0.32 ; \mathrm{p}=0.002)$ (fig. 3 ).

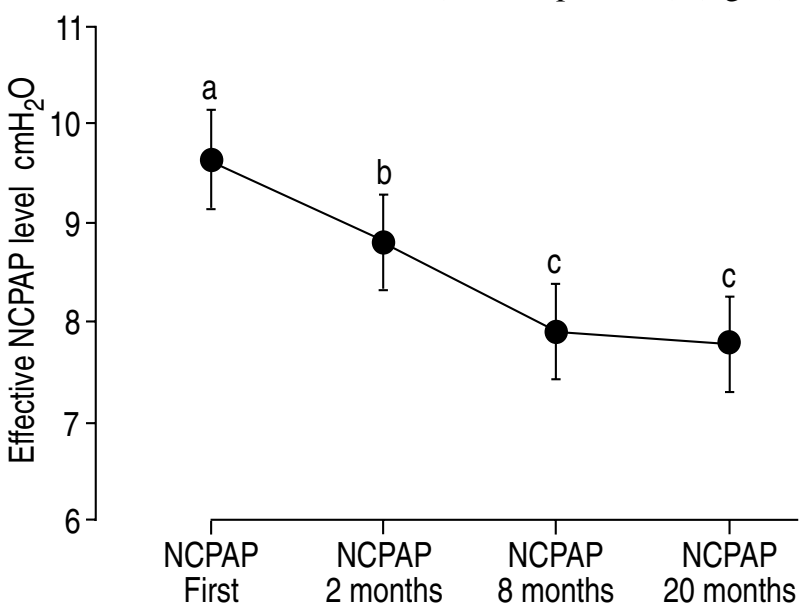

Fig. 1. - Mean \pm SEM values of the effective nasal continuous positive airway pressure (NCPAP) level measured at the different visits. This pressure level progressively decreased with time, the difference being significant after 2 and 8 months of NCPAP therapy. Values with different letters are significantly different from one another. Mean \pm SEM. Note that the vertical axis is magnified and cut-off from zero.

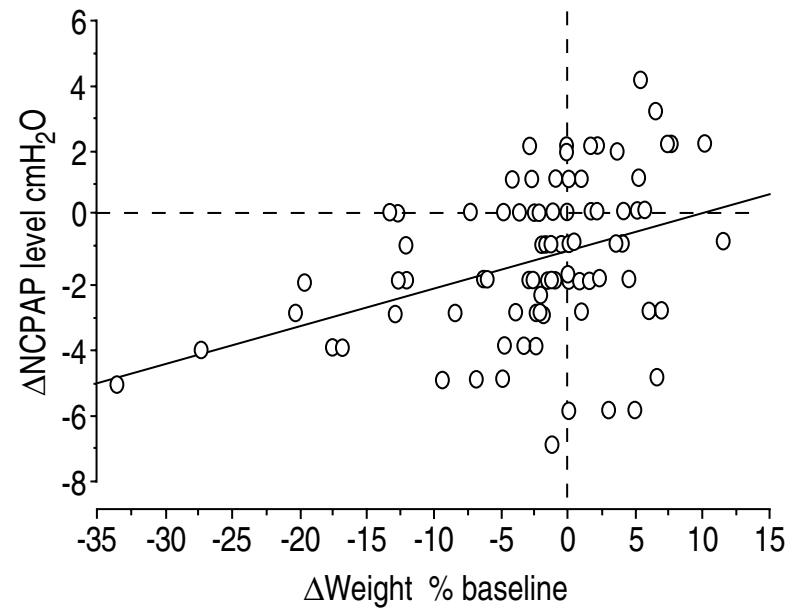

Fig. 2. - Relationship between weight changes (differences in $\%$ of baseline values) and changes in the effective nasal continuous positive airway pressure (NCPAP) level for the three NCPAP visits. There was a poor but significant relationship between these two variables $(\mathrm{r}=0.37 ; \mathrm{p}<0.0001)$

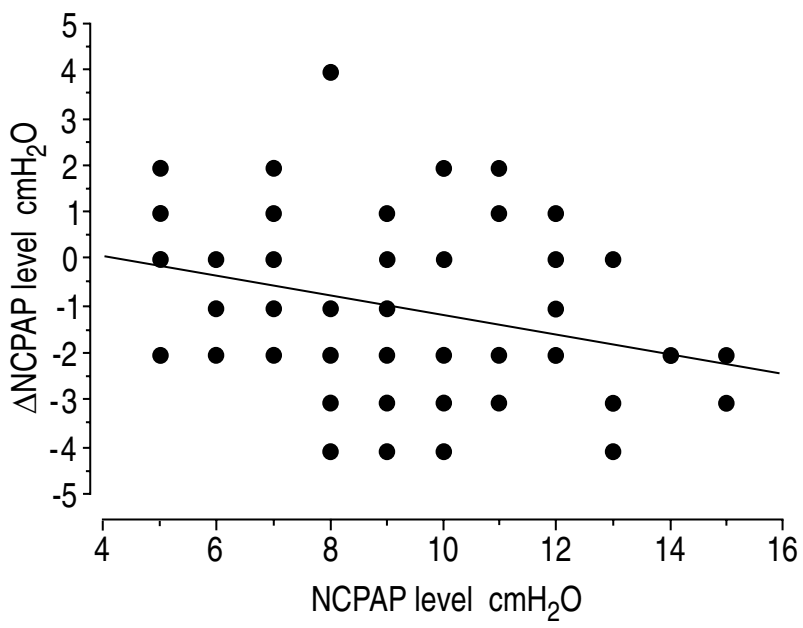

Fig. 3. - Relationship between changes in the nasal continuous positive airway pressure (NCPAP) level (difference in pressure between two successive visits) and the previous visit NCPAP level for the first two NCPAP trials ( 2 months- 8 months). The higher the pressure level, the more it could be decreased with time. The relationship between these variables was poor $(r=0.32$; $\mathrm{p}<0.002)$. 


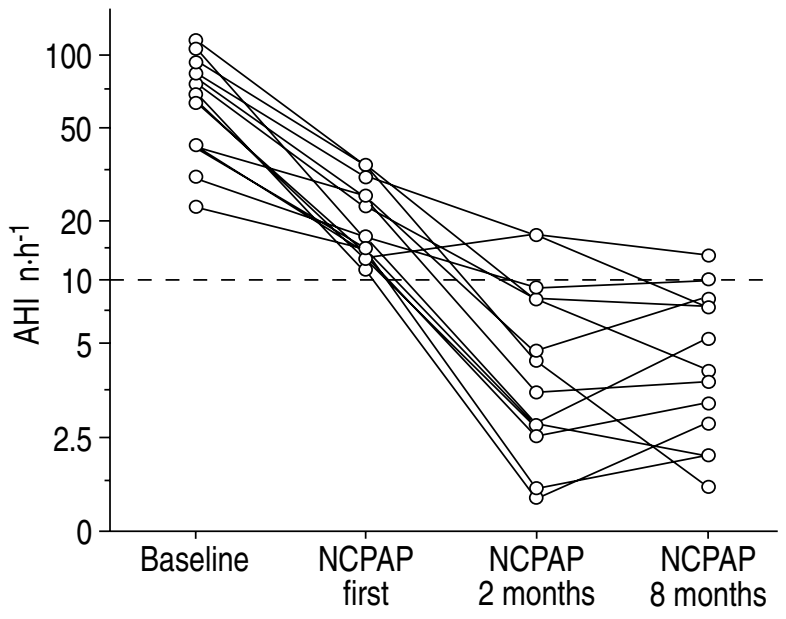

Fig. 4. - Individual values of the apnoea+hypopnoea index (AHI) obtained at the different visits in the 13 patients who tolerated only a suboptimal nasal continuous positive airway pressure (NCPAP) level during the first NCPAP trial. In 11 of these patients, the sleep-related breathing disorders returned to the normal range $\left(<10 n \cdot h^{-1}\right)$ after 2 months of NCPAP. The index values are given on a logarithmic scale for clarity.

In 13 patients, AHI remained above $10 \mathrm{n} \cdot \mathrm{h}^{-1}$ at the first NCPAP trial $\left(19.4 \pm 2.1 \mathrm{n} \cdot \mathrm{h}^{-1}\right.$; range $\left.12-32 \mathrm{n} \cdot \mathrm{h}^{-1}\right)$ because the effective NCPAP level was not tolerated. The range of NCPAP level applied that was tolerated ranged $7-15 \mathrm{cmH}_{2} \mathrm{O}\left(11.5 \pm 0.7 \mathrm{cmH}_{2} \mathrm{O}\right)$. Body mass index and baseline apnoea+hypopnoea index were among the highest values of the group $\left(40.7 \pm 2.7 \mathrm{~kg} \cdot \mathrm{m}^{-2}\right.$ and $63.9 \pm 7.8 \mathrm{n} \cdot \mathrm{h}^{-1}$, respectively). However, despite a suboptimal NCPAP level, sleep architecture and sleep fragmentation improved at the first NCPAP trial (baseline and NCPAP arousal indices: $62.0 \pm 2.9$ and $15.6 \pm 2.2$ $\mathrm{n} \cdot \mathrm{h}^{-1}$, respectively) as well as the nocturnal $\mathrm{SaO}_{2}$ falls $(\%$ total sleep time $<90 \% \mathrm{SaO}_{2}$ decreasing from $40.9 \pm 8.5$ to $21.9 \pm 7.7 \%$ ). All patients reported a dramatic subjective improvement in sleep quality and a decrease in diurnal hypersomnolence with NCPAP. Their weight remained unchanged at the different visits (baseline $106.5 \pm 6.3 \mathrm{~kg}$; after 2 months $103.3 \pm 5.8 \mathrm{~kg}$; and after 8 months $103.0 \pm$ $5.5 \mathrm{~kg}$ ). After 2 months of NCPAP therapy, the AHI was $<10$ in 11 of the initially suboptimally treated patients (fig. 4). At this visit, the percentage total sleep time $<90 \% \mathrm{SaO}_{2}$ was $8.8 \pm 4$.6. In seven of these subjects, an effective NCPAP level was achieved at a pressure ranging $2-4 \mathrm{cmH}_{2} \mathrm{O}$ lower than the initial suboptimal pressure. In these 13 patients, there was no relationship between weight and NCPAP level changes.

\section{Discussion}

This study demonstrates that the required NCPAP level progressively decreases during the first 8 months of use, and that the changes in body weight poorly contribute to the changes in the effective NCPAP level.

Recent reports have shown that NCPAP benefits may be prolonged after its interruption following long-term treatment $[8,9]$. The improvement reported by RAUSCHER et al. [8] was more important in patients with the most severe disorders. Similarily, the prolonged beneficial effects observed by LEECH et al. [9] after 6-46 months of NCPAP therapy occurred in patients with a respiratory disturbance index greater than $50 \mathrm{n} \cdot \mathrm{h}^{-1}$. SchwARTZ et al. [21] reported a small but significant decrease in the closing pressure after NCPAP therapy, and a positive relationship between upper airway collapsibility and the severity of sleep-related breathing abnormalities $[21,22]$. We found that the decrease in the NCPAP effective level tended to depend on the previous pressure level, and that the decrease in the effective positive pressure plateaued after 8 months of NCPAP therapy. Therefore, it can be assumed that the amount of NCPAPinduced decrease in upper airways collapsibility depends on its baseline value until the mean effective pressure has been reached, with no further improvement over time.

In previous studies, the delayed effects on NCPAP could not be explained by changes in body weight $[8$, 9]. Changes in body weight could account for only $13 \%$ of the changes in the effective NCPAP level that we observed, and the decrease in the pressure level occurred even when body weight remained unchanged. However, the influence of the changes in body weight on the individual decrease in pressure level may be explained by the importance of this parameter on upper airway collapsibility [21].

Recent reports suggest that the effective compliance to NCPAP is overestimated by questionnaires and that less than $50 \%$ were regular users [23]. Therefore, one could question the compliance to the treatment, and whether our results are effectively the consequence of regular NCPAP use. All our patients complained of daytime sleepiness, difficulty in concentration, and automatic behaviour that interferred with their professional activities. All these symptoms subjectively improved with NCPAP. Since these factors are good predictors of regular use [23], we are confident that NCPAP was regularily employed and that our results are the consequence of its regular use as assessed by the records of the meters of the machines. Even if NCPAP use was not objectively measured in all our subjects, it is accepted that its use is associated with a correction of haemodynamic [3], ventilatory [9, 24] and neurophsychological [25] abnormalities, and with changes in upper airway structures [10], and collapsibility [21].

The main mechanisms accountable for the delayed effect of NCPAP are: an improvement in upper airway morphology, a correction of sleep fragmentation, and changes in ventilatory control. An increase in the minimal pharyngeal cross-sectional area is observed after 46 weeks of NCPAP that is correlated with the decrease in the mucosal water content [10]. This reduction in upper airway oedema could increase upper airway patency and decrease its collapsibility [26, 27]. Reversible local tissue damages could occur as a consequence of recurrent episodes of upper airway closure and the development of high levels of subatmospheric pressure. These two factors would be suppressed with correction of sleeprelated breathing disorders, accounting for a decrease in upper airway collapsibility and of the required NCPAP 
level with time. Improvement in sleep fragmentation by NCPAP could also account for the delayed effects of NCPAP. Since the electromyographic activity of the genioglossus is depressed after sleep deprivation [28], the elimination of sleep fragmentation by NCPAP can be accounted for by an improvement in the neuromuscular control of the pharynx. Improvements in diurnal hypoxaemia and hypercapnia occur after long-term treatment with NCPAP $[9,13]$. Changes in ventilatory control responsiveness are observed within a few days of an efficient treatment of apnoeic events [24, 29]. Since upper airway patency and central ventilatory activity are intimately linked [30], it is possible that changes in the sensitivity of the ventilatory control are involved in the delayed effects of NCPAP. However, since only six of our patients had diurnal hypoxaemia and hypercapnia, we do not believe that this mechanism can account for the findings in all of our study population; five of the apnoeic patients with an obesity hypoventilation syndrome had normal diurnal arterial blood gases after 2 months of NCPAP therapy.

The progressive improvement in nocturnal breathing disorders during NCPAP therapy can have important practical repercussions. The first practical consideration concerns the required frequency of control sleep studies in SAHS treated with NCPAP. Our results suggest that a 2-6 month control, and subsequent annual visits are needed to adjust the pressure level. In the experience of ourselves and others, nasal problems such as dryness and congestion are the most frequent complaints during NCPAP therapy [31]. Since these side-effects are related to nasal airflow, and indirectly to NCPAP level, the decrease in the effective pressure level may contribute to improved comfort. The second practical consideration deals with "unsuccessful" first NCPAP trials. We found that in 13 subjects, obstructive sleep-induced respiratory abnormalities persisted during the first NCPAP trial because the effective NCPAP level was not tolerated. Since all these patients reported severe daytime hypersomnolence that improved with NCPAP, they were kept on this treatment. The results obtained at the follow-up visits clearly demonstrate that the majority of these patients improved further after 2 months of NCPAP therapy. Therefore, since the first goal of the initial NCPAP therapy is to improve the consequences of sleep-related obstructive breathing disorders, the persistence of apnoeic and hypopnoeic events does not rule out NCPAP efficiency if the frequency of breathing disorders, nocturnal desaturations, and sleep disruption are improved. In such cases, home therapy with NCPAP can be initiated, recognizing that polysomnographic study should be performed within the following months to document delayed improvement and eventually reduce the pressure level. Other therapeutic methods (e.g. bilevel positive airway pressure (BiPAP)) could be used after this delay, if NCPAP failed to normalize sleep-related breathing disorders at follow-up visits.

We conclude that the effective NCPAP level decreases with time and that patients using suboptimal NCPAP levels may have immediate benefits of this therapy and further improvement over time.

\section{References}

1. Sullivan CE, Issa FG, Berthon-Jones M, Eves L. Reversal of obstructive sleep apnoea by continuous positive airway pressure applied through the nares. Lancet 1981; i: $862-865$.

2. Sériès F, Cormier Y, La Forge J. Influence of continuous positive airway pressure on sleep apnea-related desaturation in sleep apnea patients. Lung 1992; 170: 281290.

3. Malone S, Liu PP, Holloway R, Rutherford R, Xie A, Bradley TD. Obstructive sleep apnoea in patients with dilated cardiomyopathy: effects of continuous positive airway pressure. Lancet 1991; 338: 1480-1484.

4. Shiomi T, Guilleminault C, Stoohs R, Schnittger I. Leftward shift of the interventricular septum and pulsus paradoxus in obstructive sleep apnea syndrome. Chest 1991; 100: 894-902.

5. Issa FG, Sullivan CE. The immediate effects of nasal continuous positive airway pressure treatment on sleep pattern in patients with obstructive sleep apnea syndrome. Electroenceph Clin Neurophysiol 1986; 63: 10-17.

6. Sforza E, Krieger J, Weitzenblum E, Apprill M, Lampert E, Ratamaharo J. Long-term effects of treatment with nasal continuous positive airway pressure on daytime lung function and pulmonary hemodynamics in patients with obstructive sleep apnea. Am Rev Respir Dis 1990; 141: 866-870.

7. He J, Kryger MH, Zorick FJ, Conway W, Roth T. Mortality and apnea index in obstructive sleep apnea: experience in 385 male patients. Chest 1988; 94: 9-14.

8. Rauscher H, Popp W, Wanke T, Zwick H. Breathing during sleep in patients treated for obstructive sleep apnea. Chest 1991; 100: 156-159.

9. Leech JA, önal E, Lopata M. Nasal CPAP continues to improve sleep-disordered breathing and daytime oxygenation over long-term follow-up of occlusive sleep apnea syndrome. Chest 1992; 102: 1651-1655.

10. Ryan CF, Lowe AA, Li D, Fleetham JA. Magnetic resonance imaging of the upper airway in obstructive sleep apnea before and after chronic nasal continuous positive airway pressure therapy. Am Rev Respir Dis 1991; 144: 939-944.

11. Sullivan CE, Issa FG, Berthon-Jones M, Saunders NA. Pathophysiology of sleep apnea. In: Saunders NA, Sullivan CE, eds. Sleep and Breathing. New York, Dekker, 1984; pp. 299-363.

12. Sullivan CE, Grunstein RR. Continuous positive airways pressure in sleep-disordered breathing. In: Kryger MH, Roth T, Dement WC, eds. Principles and Practice of Sleep Medicine. Philadelphia, WB Saunders 1989; pp. 559-570.

13. Sforza E, Capecchi V, Lugaresi E. Haemodynamic effects of short-term nasal continuous positive airway pressure therapy in sleep apnoea syndrome: monitoring by a finger arterial pressure device. Eur Respir J 1992; 5: 858-863.

14. Chadha TS, Watson H, Birch S, et al. Validation of respiratory inductive plethysmography using different calibration procedures. Am Rev Respir Dis 1982; 125: 644-649.

15. Sériès F, Marc I. Effects of protriptyline on snoring characteristics. Chest 1993; 104: 14-18.

16. Reschtschaffen A, Kales A, eds. A manual of standardized terminology, techniques and scoring systems for sleep stages of human subjects. Bethesda, National Institutes of Health, 1968; (publication no. 204). 
17. Martin RJ, (Chairman). Indications and standards for cardiopulmonary sleep studies. Sleep 1985; 8: 371-379.

18. American Sleep Disorders Association. EEG arousals: scoring rules and examples. Sleep 1992; 15: 174-183.

19. Zar JH. In: Biostatistical Analysis. Second edn. NJ, Prentice Hall, 1984; Chap. 14.2, p. 239.

20. Srivastava MS, Carter EM. An introduction to applied multivariate statistics North Holland, NY, 1983; Chap. 7, p. 198.

21. Schwartz AR, Gold AR, Schubert N, et al. Effects of weight loss on upper airway collapsibility in obstructive sleep apnea. Am Rev Respir Dis 1991; 144: 494-498.

22. Schwartz AR Schubert N, Rothman W, et al. Effects of uvulopalatopharyngoplasty on upper airway collapsibility in obstructive sleep apnea. Am Rev Respir Dis 1992; 145: 527-532.

23. Kribbs NA, Pack AI, Kline LR, et al. Objective measurements of patterns of CPAP use by patients with obstructive sleep apnea. Am Rev Respir Dis 1993; 147: 887-895.

24. Berthon-Jones M, Sullivan CE. Time course of change in ventilatory response to $\mathrm{CO}_{2}$ with long-term CPAP therapy for obstructive sleep apnea. Am Rev Respir Dis 1987; 135: 144-147.

25. Sarkis S, Derderian MC, Bridenbaugh RH, Rajagopal KR. Neuropsychologic symptoms in obstructive sleep apnea improve after treatment with nasal continuous positive airway pressure. Chest 1988; 94: 1023-1027.

26. Wasicko MJ, Leiter JC, Erlichman JS, Stobel RJ, Bartlett D. Nasal and pharyngeal resistance after topical mucosal vasoconstriction in normal humans. Am Rev Respir Dis 1991; 144: 1048-1052.

27. Wasicko MJ, Hutt DA, Parisi RA, Neubauer JA, Mezrich $\mathrm{R}$, Edelman NH. The role of vascular tone in the control of upper airway collapsibility. Am Rev Respir Dis 1990; 141: 1569-1577.

28. Leiter JC, Knuth SL, Bartlett D. The effects of sleep deprivation on activity of the genioglossus muscle. Am Rev Respir Dis 1985; 32: 1242-1245.

29. Aubert-Tulkens G, Willems B, Veriter CI, Coche E, Stanescu DC. Increase in ventilatory response to $\mathrm{CO}_{2}$ following tracheostomy in obstructive sleep apnea. Bull Eur Physiopathol Respir 1980; 16: 587-593.

30. Sériès F, Cormier Y, Desmeules M, La Forge J. Effects of respiratory drive on upper airways in sleep apnea patients and normals. J Appl Physiol 1989; 67: 973979.

31. Hoffstein V, Viner S, Mateika S, Conway J. Treatment of obstructive sleep apnea with nasal continuous positive airway pressure. Patient compliance, perception of benefits and side-effects. Am Rev Respir Dis 1992; 145: 841-845. 